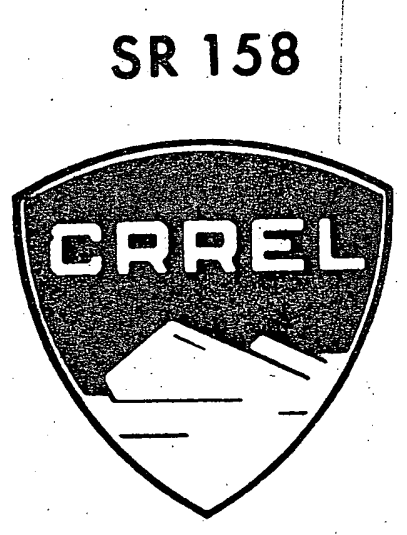

\title{
COMPOSITION AND MASS SPECTRA \\ OF IMPURITIES \\ IN MILITARY GRADE TNT VAPOR
}

\author{
R.P. Murrmann, T.F. Jenkins \\ and \\ D.C. Leggett
}

May 1971

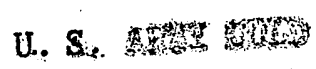

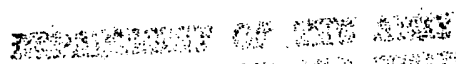

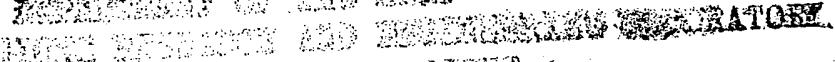

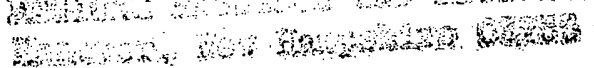

CORPS OF ENGINEERS, U.S. ARMY

COLD REGIONS RESEARCH AND ENGINEERING LABORATORY

HANOVER, NEW HAMPSHIRE 


\section{CONTENTS}

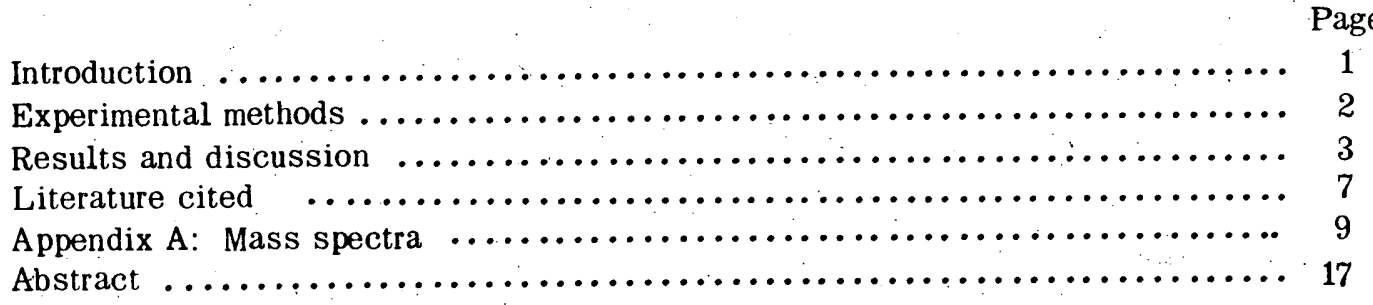

\section{ILLUSTRATIONS}

Figure

1. DNT and TNT isomers in military grade TNT $\ldots \ldots \ldots \ldots \ldots \ldots \ldots \ldots \ldots . \ldots . \ldots$

2. Equilibration of solid military grade TNT with undersaturated and supersatu-

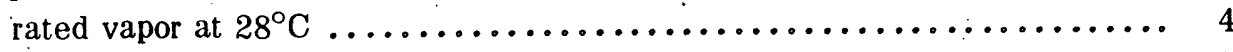

3. Mass spectra of $2,4 \mathrm{DNT}$ and $2,4,6 \mathrm{TNT} \ldots \ldots \ldots \ldots \ldots \ldots \ldots \ldots \ldots \ldots, 7$

\section{TABLES}

Table

I. Composition of the solid and the equilibrium vapor phases of typical military grade TNT 


\title{
COMPOSITION AND MASS SPECTRA OF IMPURITIES IN MILITARY GRADE TNT VAPOR
}

by

\author{
R.P. Murrmann, T.F. Jenkins, and D.C. Leggett
}

\section{INTRODUCTION}

Detection of mines by sensing associated trace gases in the atmosphere has been under investigation for several years. ${ }^{12} 3121^{14}$ In developing this concept it is envisioned that a unique chemical signature could arise from either the hardware components of mines or the explosive itself. Since the explosive is a common denominator among many types of mines, it seems reasonable that the trace gas sensing approach to mine detection should be based upon analysis for explosive vapors. Thus far, virtually no work has been reported on the characterization of volatile chemicals emitted by intact mines. Information on the composition of explosive vapors at ambient temperatures is nearly as scarce. Detailed data on the composition of vapors emitted by intact mines and explosives, influenced by factors such as type, manufacturing source, and aging, are required to define what components are actually most suitable for detection. Mines and explosives well characterized with regard to vapor characteristics should also be available for use in evaluation of the performance of detection devices in the development stage.

Military grade trinitrotoluene (TNT) is a major constituent of many military explosives. ${ }^{6}{ }^{11}$ A number of studies have been reported on the chemical analysis of solid TNT. ${ }^{7}{ }^{9} 16$.18 From . studies of these types, it is known that solid military grade TNT is nearly pure 2, 4, 6 trinitrotoluene. Small amounts of other isomeric forms of TNT as well as several isomers of dinitrotoluene (DNT) are usually present. Isomeric impurities of DNT and TNT are the predominant impurities that remain in solid military grade TNT after the final manufacturing process. Although it seems obvious that these impurities are also present in the vapor of military grade TNT, they have not been determined nor is it now practical to predict the composition of the vapor from data available on the solid phase. This lack of data on TNT vapor composition does not necesssarily reflect a lack of interest in determination of the impurities. Rather, the data are lacking because the analysis requires instrumentation that is not available in many analytical laboratories.

Several report $\mathrm{s}^{510}{ }^{15}$ contain data on the vapor pressure of $2,4,6$ TNT above ambient temperatures. The data of Edwards ${ }^{5}$ have been extrapolated ${ }^{3}{ }^{14}$ to obtain an estimate of about $10^{-6} \mathrm{~mm}$ for the vapor pressure of $2,4,6 \mathrm{TNT}$ at $25^{\circ} \mathrm{C}$. Recently, Coates et al.$^{3}$ attempted to determine the vapor pressure of military grade TNT at room temperature. They considered their value, $1.2 \times 10^{-3}$ $\mathrm{mm}$, too high. This discrepancy could be caused in part by the presence of DNT isomeric impurities which in pure form are more volatile than 2, 4, 6 TNT.

Mass spectra of military grade TNT vapor have been published by several investigators. ${ }^{13}{ }^{17}$ The degree to which impurities influenced these results is not known. Identification of compounds which contribute ion fragments to the mass spectrum of military grade TNT is important, not only because it enables the vapor to be characterized, but because the mass spectrometer and other 


\section{COMPOSITION AND MASS SPECTRA OF IMPURITIES IN MILITARY GRADE TNT VAPOR}

types of ion fragment detectors such as the plasma chromatograph are among the few existing techniques with sufficient sensitivity and selectivity for laboratory studies and the development of field detection systems.

This investigation was undertaken to evaluate the suitability of gas chromatographic electron capture detector techniques for analysis of military grade TNT vapor, and to obtain the mass spectra of the DNT and TNT isomers commonly present as impurities in military grade TNT.

\section{EXPERIMENT.AL METHODS}

Picatinny Arsenal* provided samples of each of the 6 isomers of DNT, 4 of the 6 isomers of TNT, and freshly prepared military grade TNT. White label grade 2, 4, 6 TNT was obtained from the Eastman Kodak Company. The isomer 3, 4, 5 TNT was not available. Three samples of military grade TNT were obtained from the U.S. Army Mobility Equipment Research and Development Center (USA MERDC). $\dagger$

A Perkin Elmer Corporation Model 900 gas chromatograph equipped with flame ionization and electron capture detectors was used for analysis. The electron capture detector was selected for vapor analysis because of its inherent high sensitivity and selectivity for electrophillic compounds such as the DNT and TNT isomers. The flame ionization detector was used for analysis of the solid TNT. A Perkin Elmer Corporation Model 270-B mass spectrometer equipped with gas chromatographic and solids-probe inlets was used to determine the mass spectra of the DNT and TNT samples.

In the analysis of the vapor from the military grade TNT for isomeric impurities, approximately $0.2 \mathrm{~g}$ of the TNT powder was placed in a flask of known volume. The flask was sealed with a septum cap suitable for withdrawal of vapor samples by syringe. DNT and TNT isomers in the vapor from the solid TNT were identified by comparing the retention time of each unknown component with the known retention times of the isomers determined using the samples provided by Picatinny Arsenal. To estimate the time required to attain equilibrium between the vapor and solid TNT at room temperature $\left(28^{\circ} \mathrm{C}\right)$, the vapor was analyzed for $2,4 \mathrm{DNT}$ and $2,4,6 \mathrm{TNT}$ on a daily basis until a steady-state level was reached. Flasks which were temporarily heated to about $100^{\circ} \mathrm{C}$ to supersaturate the vapor phase were also analyzed periodically. The isomeric composition of the equilibrium vapor was then determined chromatographically.

The solid military grade TNT used in these experiments was also analyzed for DNT and TNT isomeric impurities. In this analysis, $0.200 \mathrm{~g}$ of the solid TNT was dissolved in $1 \mathrm{ml}$ of benzene. The solution was chromatographed using the flame ionization detector.

In all these experiments, chromatographic conditions included use of a $12-\mathrm{ft} \times 1 / \frac{1}{8}$-in. column containing $15 \%$ DC200 on Anakrom ABS operated isothermally at $190^{\circ} \mathrm{C}$ with a carrier gas flow rate of $40 \mathrm{ml} \mathrm{min}^{-1}$. The carrier gas for the flame ionization detector was helium, and that for the electron capture detector operated in the pulse mode was $5 \%$ methane in argon. For analysis of the TNT vapor, 500- $\mu$ liter samples were used.

Two methods were used to obtain mass spectra of the various DNT and TNT isomers, and the military grade TNT samples provided by USA MERDC. By the first method, individual samples were dissolved in benzene and were chromatographed into the ion source of the mass spectrometer. The mass spectrum was recorded as the compound eluted from the column as indicated by a concurrent increase in total ion current at the appropriate retention time. These mass spectra were obtained

* Courtesy of Mr. C. Ribaudo, Explosives Laboratory, Picatinny Arsenal.

$\dagger$ Courtesy of Mr. M. Kemp, Research Division, Intrusion Detection and Sensor Laboratory, USA MERDC. 
at an ionization voltage of $75 \mathrm{eV}$. By the second method, a quartz tube containing several milligrams of sample was inserted directly into the mass spectrometer ion source using the solids-probe. The solids-probe and ion scurce housing were both maintained at $60^{\circ} \mathrm{C}$. The mass spectrum of the vapor from each compound was recorded at several ionization voltages ranging from $75 \mathrm{eV}$ to $14 \mathrm{eV}$.

\section{RESULTS AND DISCUSSION}

The DNT and TNT isomers present in the vapor from the fresh military grade TNT after equilibration for one day are indicated by the top chromatogram shown in Figure 1. The lower chromatogram was obtained using a benzene solution prepared using individual DNT and TNT isomers. By comparison of the chromatograms, the presence in the TNT vapor of the principal componest of solid TNT, 2, 4, 6 TNT, and a najor impurity peak corresponding to 2, $3 \mathrm{DNT}, 2,4 \mathrm{DNT}$, and 3, 5 DNT is clearly evident. Although no attemp: was made to resolve the DNT isomer peak, the principal component is almost certainly 2, 4 DNT. This is because the formation of 2,4 DNT is favored over that of the other DNT isomers in synthesis of $2,4,6$ 'TNT. Furthermore, previous analyses of solid TNT show that 2,4 DNT is the major DNT impurity after final processing. ${ }^{78} 91618$ Also present in the vapor phase are smaller amounts of $2,5 \mathrm{DNT}, 2,3,4 \mathrm{TNT}, 2,3,5 \mathrm{TNT}$, and possibly 2, 6 DNT. The electron capture detector response was attenuated by a factor of 160 , indicating that the sensitivity of this detectcr is sufficient for analysis of DNT and TNT isomers ir small volumes of the vafor phase. However, the noise level prevented use of the full sensitivity range under the particular chromatographic conditions used in this study.

Gas chromatograms obtained in estimating the time required to attain equilibrium between solid military grade TNT and the vapor phase at room temperature $\left(28^{\circ} \mathrm{C}\right)$ are shown in Figure 2. The vapor of one sample (nonheated) was analyzed during approach to equilibrium from undersaturation; the second sample was heated to supersaturate the vapor prior to equilibration. Analysis of the data showed that the 2, 4 DNT impurity concentration reached an equilibrium value in less than one day regardless of the direction of approach. For 2, 4,6 TNT, a steady-state condition was reached from undersaturation in 3 days. After supersaturation of the vapor phase, the 2, 4,6 TNT concentration was still decreasing after 4 days. Using data obtained after approaching equilibrium from undersaturation for 4 days, the vapor pressure of the $2,4,6$ TNT was calculated to be $1 \times 10^{-5}$ $\mathrm{mm}$. Our measurement was not repeated to define the accuracy of this value. Also, the experimental configuration was not ideal for rapid approach to equilibrium (high vapor phase to TNT surface area ratio) nor was the temperature precisely controlled. However, it seems worth considering that the lower value previously obtained (about $10^{-6} \mathrm{~mm}$ at $25^{\circ} \mathrm{C}$ ) by extrapolation of data taken at higher temperatures ${ }^{314}$ may be in error because of lack of equilibrium during measurement, or because of difficulty in determining thermal equilibrium at higher temperatures. ${ }^{10}$ Certainly, establishment of criteria for equilibrium should be incorporated into any dynamic method ${ }^{3}$ used to establish the vapor pressure of TNT. The other difficulty that is obvious is the possible contribution of 2,4 DNT to the total vapor pressure measurement. These considerations indicate the need for development of a more refined chromatographic method for routine analysis of component concentrations in a static system in determining the vapor characteristics of military grade TNT.

Comparison of the composition of the solid and the equilibrium vapor phases of military grade TNT is given in Table I. The concentration of each of the DNT and TNT isomeric impurities in the solid TNT was less than $0.1 \%$ and, for several of the impurities, less than $0.01 \%$. However, the concentrations of impurities in the vapor emitted by the solid were much higher, cumulatively amounting to $42 \%$ of the vapor composition. The most prominent impurity was 2,4 DNT which accounted for $35 \%$ of the vapor. Military grade TNT is almost pure 2, 4, 6 TNT; therefore, the vapor pressure of the 2, 4,6 TNT component was probably very close to that of pure 2, 4,6 TNT. 


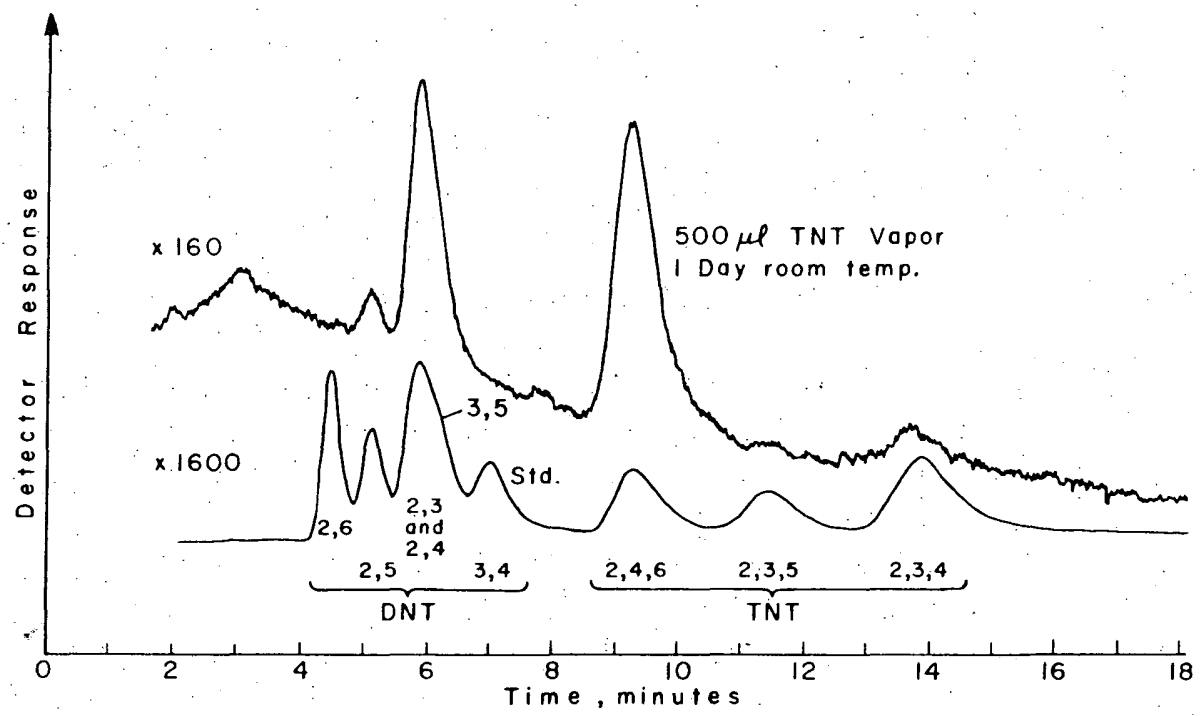

Figure 1. DNT and TNT isomers in military grade TNT.

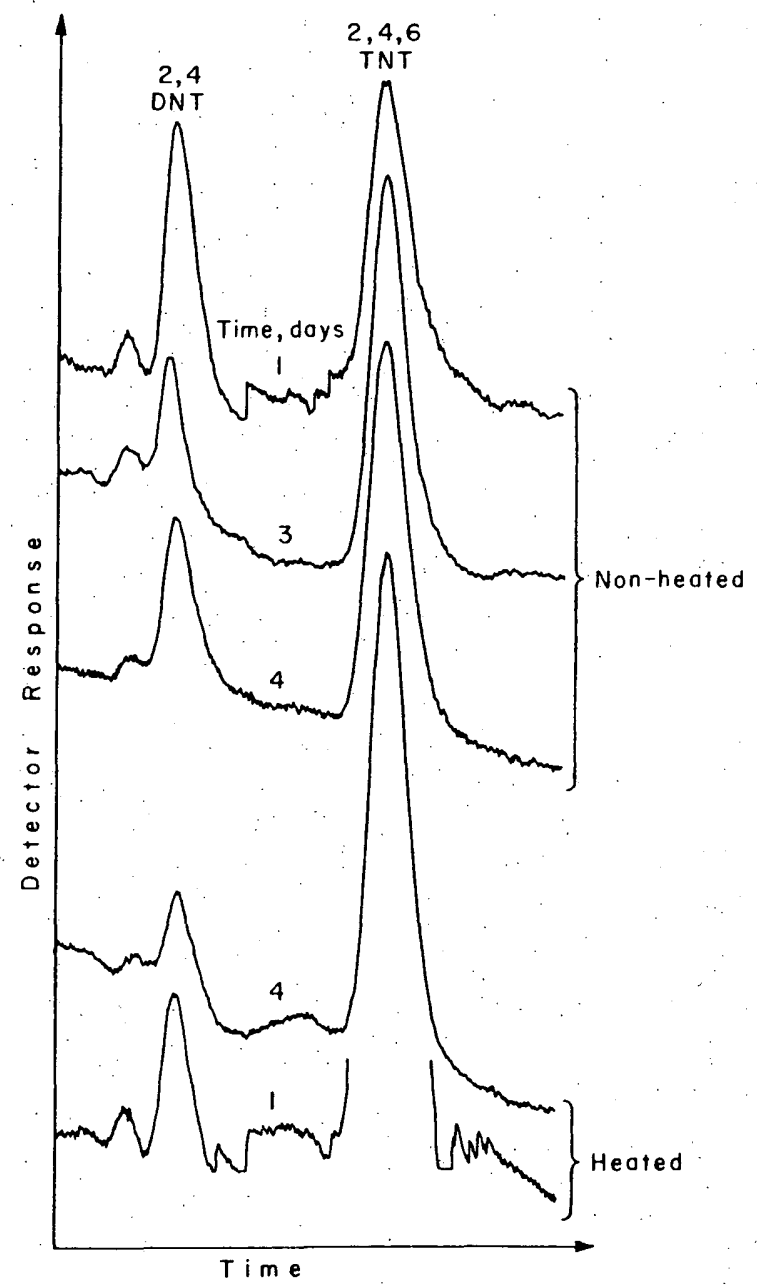

Figure 2. Equilibration of solid military grade TNT with undersaturated and supersaturated vapor at $28^{\circ} \mathrm{C}$. 
Table I. Composition of the solid and the equilibrium vapor phases of typical military grade TNT.

\begin{tabular}{lcc} 
Compound & $\begin{array}{c}\text { Solid phase } \\
\text { composition }(\%)\end{array}$ & $\begin{array}{c}\text { Vapor phase } \\
\text { composition }(\%)\end{array}$ \\
\hline $2,4,6 \mathrm{TNT}$ & 99.80 & $58\left(1 \times 10^{-5} \mathrm{~mm}\right)$ \\
$2,3,5 \mathrm{TNT}$ & 0.08 & trace \\
$2,3,4 \mathrm{TNT}$ & 0.02 & 3 \\
$2,4 \mathrm{DNT}$ & 0.08 & 35 \\
$2,5 \mathrm{DNT}$ & $<0.01$ & 4 \\
$3,5 \mathrm{DNT}$ & $<0.01$ & trace \\
$3,4 \mathrm{DNT}$ & trace & trace \\
$2,6 \mathrm{DNT}$ & trace & trace \\
Other impurities & None detected & No determination \\
\hline
\end{tabular}

Since the vapor pressure of a component in a mixture is less than that of the pure component, it is not surprising that the contribution of each of the other TNT isomers to the total vapor pressure was less than that of $2,4,6$ TNT. Likewise, it seems reasonable that the partial pressure of the 2, 4 DNT impurity, although comparable to that of 2,4,6 TNT, was much less than the vapor pressure of pure 2, 4 DNT: $2.7 \times 10^{-2} \mathrm{~mm}$ at $28^{\circ} \mathrm{C}^{2}$ For purposes of detection, 2, 4 DNT may be as important as 2, 4, 6 TNT. This is particularly true since the 2,4 DNT impurity volatilizes much more rapidly than $2,4,6 \mathrm{TNT}$. The amount of $2,4 \mathrm{DNT}$ in munitions may decrease with aging due to its relatively high volatility; however, this impurity has always been found in both crude and production TNT. ${ }^{789} 1618$

Although a special effort was made to detect impurities other than the DNT and TNT isomers, no other compounds were observed using either the electron capture or the flame ionization detector which is sensitive to all organic compounds. This indicates that military grade TNT is remarkably free of organic compounds that might be present as a result of handling or of the manufacturing process. Consequently, compounds other than 2, 4,6 TNT and 2,4 DNT are not likely to be useful in the design of detection systems based upon emissions from military grade TNT.

The mass spectrum of vapor from each of the possible DNT and TNT isomers, with the exception of $3,4,5 \mathrm{TNT}$ which was not available, is shown as a function of ionization voltage from 75 $\mathrm{eV}$ to $14 \mathrm{eV}$ in Tables AI and AII (App. A), respectively. The data are expressed as percentage of the most intense peak (base peak) in the spectrum. These mass spectra were obtained using the solids-probe inlet method. The spectra taken with the gas chromatographic inlet system were not compiled for this report because they were virtually identical to those shown in Tables AI and AII at $75 \mathrm{eV}$.

The spectra of the DNT isomers taken at an ionization voltage of $75 \mathrm{eV}$ are consistent with those previously reported. ${ }^{4}$ Although the mass spectrum of each isomer is unique, there are similarities in the low mass range at the higher ionization voltages caused by the presence of prominent peaks at $m / e=30,39,51,63,77$, and 89 . This is not surprising in view of the similar structure of the molecules. The mass spectra of 2, 3 DNT, 2, 4 DNT, 2, 5 DNT and 2, 6 DNT in the upper mass range are characterized by a base peak at $\mathrm{m} / \mathrm{e}=165$ and a weak molecular ion peak at $m / e=182$; whereas the mass spectra of $3,4 \mathrm{DNT}$ and 3,5 DNT show a strong molecular ion peak. These differences are characteristic of nitroaromatic compounds. The first group is composed of the DNT isomers which have a methyl group adjacent to a nitro substituent, facilitating loss of hydroxyl from the molecular ion $\mathrm{M}^{+}$at $m / e=182$ to form $(\mathrm{M}-\mathrm{OH})^{+}$at $m / e=165$, the base peak. The second class of DNT isomers, which exhibit a strong $\mathrm{M}^{+}$peak, do not have this structural feature. 


\section{COMPOSITION AND MASS SPECTRA OF IMPURITIES IN MILITARY GRADE TNT VAPOR}

The spectra of the TNT isomers have not been previously reported except for $2,4,6$ TNT $^{17}$ which has essentially the same mass spectrum as production grade TNT. ${ }^{13}$ The spectra of the TNT isomers are individually unique but exhibit at the higher ionization voltages common intense peaks at $\mathrm{m} / \mathrm{e}=30,39,51,63,77,89,134,180$, and 210 . The base peak in each spectrum occurs at $m / e=210$, with the exception of $2,3,4 \mathrm{TNT}$ which has a base peak at $m / e=134$. As in the case of the DNT isomers, the base peak at 210 arises because of loss of hydroxyl from the parent ion. Although $3,4,5$ TNT was not available the spectrum of this isomer should be unique, showing little or no $(\mathrm{M}-\mathrm{OH})^{+}$peak at $m / e=210$ and a relatively strong $\mathrm{M}^{+}$peak at $m / e=227$ due to the absence of adjacent nitro and methyl groups.

As is commonly observed in the mass spectra of all compounds, the mass spectra of both the DNT and TNT isomers are simplified upon lowering of the ionization voltage due to decreased secondary fragmentation of the molecular ion. The molecular ion peak also becomes relatively more prominent in the normalized mass spectrum provided that the ionization voltage exceeds the ionization potential of the parent molecule. For development of a detection system based upon moleculär fragmentation, use of high ionization voltage $(50-75 \mathrm{eV})$ would be an advantage since both total and specific ion current and, consequently, detection sensitivity drop of rapidly with decreasing ionization voltage.

The mass spectra of 2, 4 DNT and 2, 4,6 TNT, the major components in the military grade TNT vapor, taken at an ionization voltage of $75 \mathrm{eV}$ have been plotted in Figure 3 for comparison. As indicated previously, the normalized mass spectra of these compounds are virtually the same in the low mass range from $m / e=30$ to 89 . Prominent peaks not common toiboth compounds include the base peaks at $m / e=165$ and 210 ; and the molecular ion peaks at $m / e=182$ and 227 for 2,4 DNT and 2, 4, 6 TNT, respectively. In development of a fragment ion detector system, it should be possible to tune on ion peaks, which are characteristic of military grade TNT but which are not produced by compounds normally present in the atmosphere under a range of environmental conditions. The molecular ion peak of $2,4,6$ TNT might be a unique choice but this ion fragment represents an extremely small fraction of the total ion current, and, thus, would not be a good selection in terms of sensitivity. The same is true of the molecular ion peak of 2,4 DNT for which the uncertainty of presence as an impurity may be an additional disadvantage.

Although specificity may preclude selection of useful peaks in the low mass range there is a possible advantage in that the spectra of both compounds reinforce each other in this range. Moreover, it is quite likely that development of a detection system for use in the low mass range would be considerably simplified due to low resolution requirements. Of the prominent peaks in the low mass range, those at $m / e=30,39,51$, and 78 are commonly produced during the fragmentation of many types of molecules, ${ }^{4}$ whereas the mass peaks at $m / e=63$ and 89 are produced by very few compounds, none of which produce both peaks. Thus, the presence of peaks at $\mathrm{m} / e=63$ and 89 in an ion fragmentation pattern could be diagnostic for the presence of military grade TNT. This contention is supported by the fact that we have never encountered either ion fragment in the mass spectral analysis of trace gases concentrated from many atmospheric air samples.

The mass spectra of vapor from the military grade TNT samples from USA MERDC are given in Table AIII. They were obtained using the solids-probe inlet to the ion source housing, both of which were maintained at $60^{\circ} \mathrm{C}$. These mass spectra, which are in agreement with the mass spectra previously reported ${ }^{13}$ for military grade TNT, all correspond to the mass spectrum of $2,4,6$ TNT (Table AII). Peaks diagnostic for the presence of $2,4 \mathrm{DNT}$ at $\mathrm{m} / e=119,165$, and 182 were not observed even though 2,4 DNT was shown in this study to be a major component of military grade TNT vapor. 

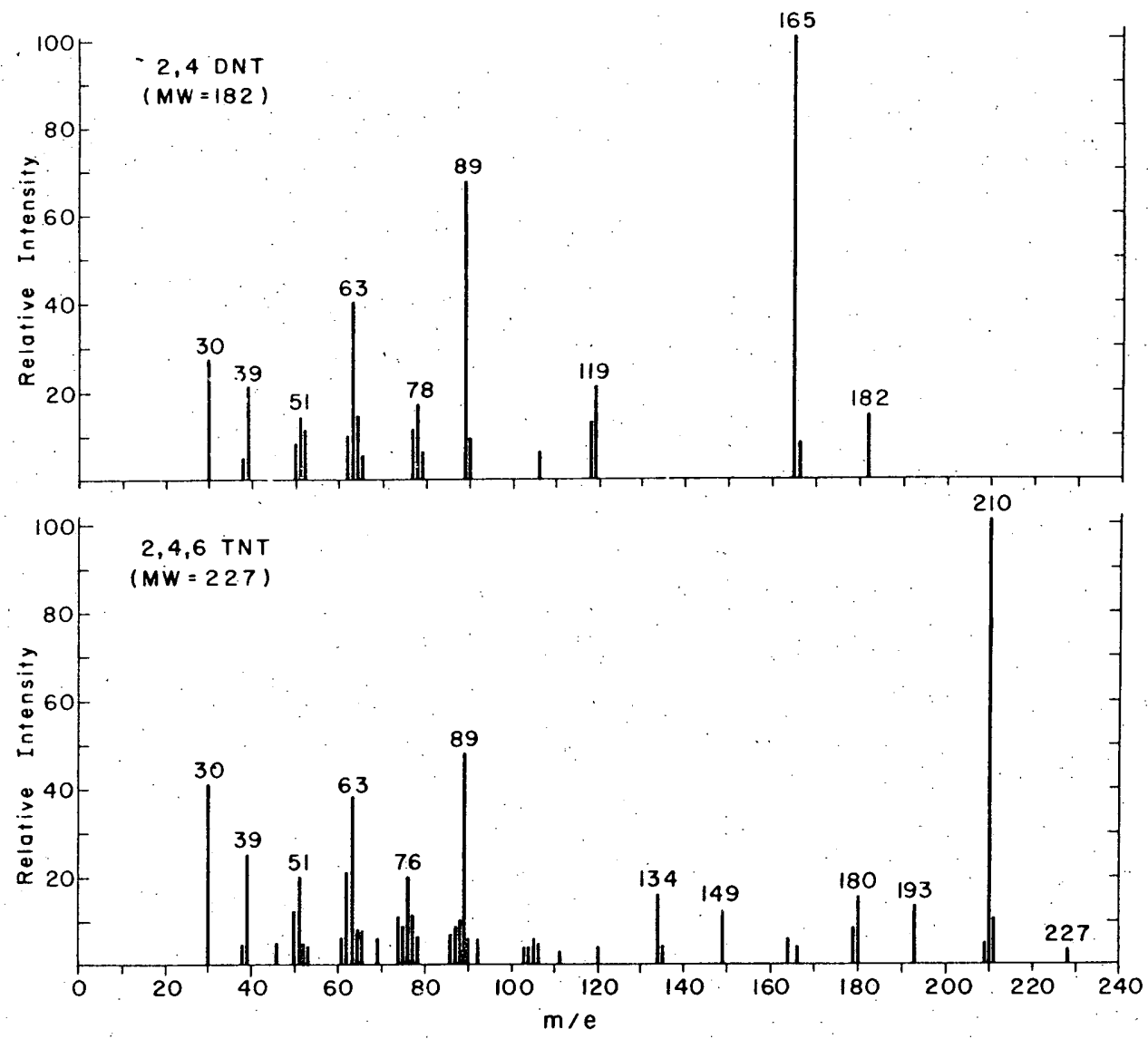

Figure 3. Mass spectra of 2, $4 D N T$ and 2, 4, 6 TNT.

Although the data are not shown, we did verify chromatographically that 2,4 DNT was present in the TNT samples DCT 1 and DCT 2. The explanation for this inconsistency is related to the conditions under which the mass spectra were taken. The ion source housing in which the sample is placed is maintained under a high vacuum of $10^{-6}$ to $10^{-7} \mathrm{~mm}$ by continuous pumping. Earlier it was shown that the volatilization rate of 2,4 DNT from the solid TNT is relatively rapid. Under these conditions the TNT granules would rapidly be depleted of 2,4 DNT. Thus, it seems reasonable that no evidence for the presence of 2,4 DNT was found even though it was originally present in the sample.

\section{LITERATURE CITED}

1. Anderson, D.M.; F.B. Kistner and M.J. Schwarz (1969) The mass spectra of volatile constituents in military explosives. U.S. Army Cold Regions" Research and Engineering Laboratory (USA CRREL) Special Report 105 (AD 699325).

2. Belknap, H.J.; K.R. Burson; E.L. Jones; D. Andrychuk and J. Ritchie (1965) Study of soil gas behavior pertinent to land mine detection. Texas Instruments, Inc., Dallas, Texas.

3. Coates, A.D.; E. Freedman and L.P. Kuhn (1970) Characteristics of certain military explosives. Ballistics Research Laboratory Report No. 1507.

4. Cornu, A. and R. Massot (1967) First supplement to compilation of mass spectral data. London: Heyden and Son, Ltd.

5. Edwards, G. (1950) The vapor pressure of 2, 4,6 trinitrotoluene. Transactions of the Faraday Society, vol. 46, p. 423-427. 


\section{LITERATURE CITED (Cont'd)}

6. For eign Science and Technology Center, U.S. Army, Washington, D.C. (1965) Handbook of foreign explosives.

7. Gehring, D.G. (1970) Identification of impurities in $\alpha$-trinitrotoluene by nuclear magnetic resonance spectroscopy. Analytical Chemistry, vol. 42, p. 898-902.

8. Gehring, D.G. and G.S. Reddy (1968) Nuclear magnetic resonance examination and determination of the di- and trinitrotoluene isomers in 2, 4, 6 trinitrotoluene. Analytical Chemistry, vol. 40, p. 792-795.

9. Gehring, D.G. and J.E. Shirk (1967) Separation and determination of trinitrotolue ne isomers by gas chromatography. Analytical Chemistry, vol. 39, p. 1315-1318.

10. Lenchitz, C. and R.W. Velicky (1970) Vapor pressure and heat of sublimation of three nitrotoluenes. Journal of Chemical Engineering Data, vol. 15, p. 401-403.

11. U.S. Army Materiel Command (1967) Engineering design handbook: Explosive series. Properties of explosives of military interest. AMCP 706-177.

12. McKee, H.C. and H.P. Burchfield (1961) Clathrate sniffer evaluation. Southwest Research Institute, San Antonio, Texas.

13. Murrmann, R.P.; Y. Nakano; T.J. Simpson; D.C. Leggett and D.M. Anderson (In press) Influence of soil an detection of buried explosives and mines by trace gas analysis. USA CRREL Research Report 288.

14. Nicholson, B.J. and T.S. Shilliday (1967) Brief review on vapors from explosives and their detertion. Remote Area Conflict Information Center, Battelle Memorial Institute, Columbus, Ohio.

15. Robertson, A.J.B. (1948) The decomposition, boiling, and explosion of trinitrotoluene at high temperatures. Transactions of the Faraday Society, vol. 44, p. 977-983.

16. Rowe, M.L. (1966). Determination of $2,4,6$ trinitrotoluene in castable explosives by gas chromatography. Journal of Gas Chromatography. Nov, p. 420-421.

17. Volk, F. and H. Schubert (1968) Massenspektrometrische untersuchungen von Explosivstoffen. Explosivestoff ee 16:2 - 10 .

18. Yasuada, S.K. (1964) Identification of impurities in $a$-trinitrotoluene by thin-layer chromatography. Journal of Chromatography vol. 13, p. 78-82. 
APPENDIX A: MASS SPECTRA

1 
Table AI. Mass spectra of dinitrotoluene isomers at various ionization voltages.

2, 3 DNT

onization voltage $(\mathrm{eV})$

\begin{tabular}{rrrrrrrr} 
& 75 & 50 & 30 & 20 & 18 & 16 & 14 \\
\hline 30 & 18 & 20 & 15 & 12 & 8 & 12 & 12 \\
38 & 4 & 4 & & & & & \\
39 & 20 & 22 & 15 & 5 & 4 & & \\
50 & 6 & 5 & 2 & & & & \\
51 & 16 & 16 & 11 & 4 & 2 & & \\
52 & 24 & 26 & 25 & 12 & 10 & & \\
53 & 11 & 12 & 12 & 9 & 7 & & \\
62 & 5 & 6 & & & & \\
63 & 22 & 24 & 14 & 2 & 3 & & \\
64 & 11 & 12 & 11 & 2 & 5 & & \\
65 & 5 & 6 & 5 & 3 & 8 & & \\
66 & & & & 3 & 7 & & \\
74 & & & & & & & \\
75 & & & $\vdots$ & & & & \\
76 & & & & & & \\
77 & 16 & 17 & 17 & 12 & 8 & & \\
78 & 12 & 13 & 13 & 10 & 9 & & \\
79 & & & & & & & \\
89 & 17 & 19 & 18 & 5 & 2 & & \\
90 & 5 & 5 & 5 & 3 & 1 & & \\
91 & 7 & 7 & 7 & 5 & 4 & & \\
92 & & & & & & \\
94 & & & & & & \\
104 & & & & & & \\
105 & 3 & 4 & 3 & 3 & 2 & \\
106 & & & & & & \\
108 & & & & & & \\
118 & & & & & & \\
119 & & & & & & \\
120 & & & & & & \\
121 & & & & & & & \\
134 & & & & & & \\
135 & 59 & 62 & 57 & 64 & 64 & 32 & 26 \\
136 & & & & & & & \\
148 & & & & & & \\
165 & 100 & 100 & 100 & 100 & 100 & 100 & 100 \\
166 & 8 & 9 & 9 & 9 & 9 & 15 & 28 \\
182 & 22 & 21 & 23 & 26 & 26 & 24 & 45
\end{tabular}

$$
\text { 2, } 4 \text { DNT }
$$

Ionization voltage $(\mathrm{eV})$

\begin{tabular}{rrrrrrrr} 
& 75 & 50 & 30 & 20 & 18 & 16 & 14 \\
\hline 30 & 27 & 27 & 22 & 14 & & \\
38 & 5 & 4 & 1 & & & \\
39 & 21 & 23 & 13 & 3 & & \\
50 & 8 & 7 & 2 & & & \\
51 & 14 & 16 & 9 & 1 & & \\
52 & 11 & 11 & 10 & 5 & & \\
53 & & & & & & \\
62 & 10 & 9 & 2 & & & \\
63 & 40 & 41 & 27 & 5 & & \\
64 & 14 & 16 & 13 & 3 & & \\
65 & 5 & 5 & 4 & 2 & \\
66 & & & & & \\
74 & & & & & \\
75 & & & & & \\
76 & & & & & \\
77 & 11 & 11 & 9 & 5 & \\
78 & 17 & 16 & 15 & 12 & \\
79 & 6 & 5 & 4 & 4 \\
89 & 67 & 67 & 60 & 24 & \\
90 & 9 & 28 & 26 & 17 & \\
91 & & & & \\
92 & & & & & \\
94 & & & & & \\
104 & & & & & \\
105 & & & & \\
106 & 6 & 8 & 6 & 5 & \\
108 & & & & \\
118 & 13 & 10 & 11 & 10 & \\
119 & 21 & 21 & 19 & 20 & \\
120 & & & & & \\
121 & & & & & \\
134 & & & & & \\
135 & & & & & \\
136 & & & & & \\
148 & & & & & \\
165 & 100 & 100 & 100 & 100 & \\
166 & 8 & 8 & 8 & 8 & \\
182 & 14 & 13 & 16 & 14 & \\
& & & & &
\end{tabular}

2, 5 DNT

Ionization voltage $(\mathrm{eV})$

\begin{tabular}{|c|c|c|c|c|c|c|c|}
\hline & 75 & 50 & 30 & 20 & 18 & 16 & 14 \\
\hline 30 & 51 & 45 & 48 & 23 & 22 & 15 & 18 \\
\hline 38 & 8 & 7 & 2 & & & & \\
\hline 39 & 33 & 34 & 17 & 3 & & & \\
\hline 50 & 14 & 12 & 5 & & & & \\
\hline 51 & 24 & 30 & 19 & 3 & & & \\
\hline 52 & 25 & 26 & 17 & 4 & 5 & & \\
\hline 53 & 8 & 6 & 6 & 2 & & & \\
\hline 62 & 13 & 13 & 2 & & & & \\
\hline 63 & 48 & 51 & 28 & 5 & & & \\
\hline 64 & 23 & 24 & 16 & 6 & & & \\
\hline 65 & 12 & 11 & 9 & 3 & . & & \\
\hline 66 & & & & & & & \\
\hline 74 & 8 & 4 & & & & & \\
\hline 75 & 10 & 6 & 4 & & & & \\
\hline 76 & & 7 & 7 & & & & \\
\hline 77 & 15 & 19 & 15 & 6 & 5 & & \\
\hline 78 & 28 & 31 & 31 & 16 & 16 & 9 & \\
\hline 79 & 10 & 10 & 10 & 7 & & & \\
\hline 89 & 66 & 79 & 75 & 19 & 8 & 5 & \\
\hline 90 & 31 & 37 & 45 & 16 & 14 & 8 & \\
\hline
\end{tabular}

$\begin{array}{lllllll}31 & 37 & 45 & 16 & 14 & 8\end{array}$

$\begin{array}{rrrrrrr}91 & 24 & 17 & 17 & 13 & 8 & 9 \\ 92 & 12 & 14 & 14 & 10 & 10 & 6\end{array}$

94

$\begin{array}{lllllllll}105 & 8 & 9 & 9 & 4 & 5 & 8\end{array}$

$\begin{array}{rrrrrr}106 & 13 & 12 & 13 & 7 & 9 .\end{array}$

108

$\begin{array}{rrrrrrr}119 & 34 & 32 & 36 & 33 & 35 & 29\end{array}$

135

$\begin{array}{llllllll}165 & 100 & 100 & 100 & 100 & 100 & 100 & 100\end{array}$

$\begin{array}{llllllll}166 & 15 & 16 & 15 & 19 & 19 & 20 & 20\end{array}$ 


\section{2, 6 DNT}

\begin{tabular}{rrrrrrrr} 
& 75 & 50 & 30 & 20 & 18 & 16 & 14 \\
\hline 30 & 16 & 19 & 20 & 10 & 10 & 9 & \\
38 & 6 & 5 & 2 & & & & \\
39 & 24 & 22 & 18 & 5 & 4 & & \\
50 & 11 & 10 & 6 & & & & \\
51 & 23 & 23 & 21 & 7 & 6 & & \\
52 & 15 & 19 & 17 & 8 & 2 & & \\
53 & 6 & 5 & 8 & 5 & 3 & & \\
62 & 11 & 9 & 3 & & & & \\
63 & 41 & 39 & 27 & 6 & 9 & & \\
64 & 19 & 19 & 21 & 4 & & & \\
65 & 5 & 5 & 8 & 4 & & & \\
66 & & & & & & & \\
74 & 5 & 4 & & & & & \\
75 & 14 & 13 & 12 & 4 & & & \\
76 & 9 & 8 & 9 & 4 & & & \\
77 & 22 & 19 & 30 & 14 & 9 & & \\
78 & 19 & 16 & 26 & 24 & 16 & 18 & 26 \\
79 & 7 & 7 & 4 & 8 & 9 & 11 & \\
89 & 34 & 32 & 41 & 6 & & & \\
90 & 31 & 29 & 36 & 22 & 22 & 9 & \\
91 & 16 & 14 & 21 & 12 & 10 & & \\
92 & & & & 2 & & & \\
94 & & $\cdots$ & &. & & & \\
104 & 6 & 6 & 9 & 8 & 9 & 8 & \\
105 & & & & & & & \\
106 & & & $\ddots$ & & & & 12 \\
108 & & & & & & & \\
118 & & & & & 8 & & \\
119 & & & & - & & \\
120 & & & & & \\
121 & 15 & 14 & 20 & 12 & 6 & & \\
134 & & & & 9 & 12 & 16 & 14 \\
135 & 14 & 12 & 17 & 13 & 15 & 16 & 13 \\
136 & & & & & & & \\
148 & 15 & 14 & 19 & 18 & 18 & 18 & 12 \\
165 & 100 & 100 & 100 & 100 & 100 & 100 & 100 \\
166 & 8 & 8 & 12 & 12 & 15 & 12 & 17 \\
182 & 2 & 2 & 3 & 3 & 3 & 3 & 5
\end{tabular}

Table AI (Cont'd). Nass spectra of dinitrotoluene isomers at various ionization voltages.

$$
\text { 3, } 4 \text { DNT }
$$

lonization voltage $(\mathrm{eV})$

\begin{tabular}{|c|c|c|c|c|c|c|c|}
\hline & 75 & 50 & 30 & 20 & 18 & 16 & 14 \\
\hline 30 & 100 & 100 & 100 & 100 & 100 & 83 & 42 \\
\hline 38 & 6 & 5 & & & & & \\
\hline 39 & 36 & 38 & 25 & 8 & 4 & 3 & \\
\hline 50 & 11 & 11 & 4 & & & & \\
\hline 51 & 18 & 20 & 13 & & & & \\
\hline 52 & 27 & 32 & 28 & 9. & 7. & & \\
\hline 53 & 15 & 16 & 14 & 11 & 10 & 7 & \\
\hline 62 & 9 & 10 & 2 & & & & \\
\hline 63 & 27 & 33 & 20 & 2 & & & \\
\hline 64 & 14 & 16 & 11 & 3 & & & \\
\hline 65 & 18 & 21 & 18 & 14 & 11 & 12 & 2 \\
\hline 66 & 19 & 20 & 19. & 20 & 20 & $14^{\circ}$ & 5 \\
\hline $\begin{array}{l}74 \\
75\end{array}$ & & & & & & & \\
\hline 76 & $\cdots$ & & & & & & \\
\hline 77 & 16 & 19 & 16 & 9 & 7 & & \\
\hline 78 & 32 & 35 & 31 & 25 & 20 & 13 & \\
\hline 79 & & & & & & & \\
\hline 89 & 19 & 32 & 26 & 4 & & & \\
\hline 90 & 6 & 8 & 5 & 2 & & & \\
\hline 91 & 5 & 5 & 4 & 3 & 3 & & \\
\hline 92 & & & & & & & \\
\hline 94 & 16 & 25 & 22 & 23 & 22 & 23 & 8 \\
\hline 104 & & & & & & & \\
\hline 105 & 4 & 6 & 5 & 4 & 4 & 2 & \\
\hline 106 & & & & & & & \\
\hline 108 & 3 & 3 & 3 & 2 & 3 & 2 & \\
\hline 118 & & & & & & & \\
\hline 119 & & & & & . & & \\
\hline 120 & & & & & & & \\
\hline 121 & & & & & & & \\
\hline 134 & & & & & & & \\
\hline 135 & & & & & & & \\
\hline 136 & & & & & & & \\
\hline 148 & & & & & & & \\
\hline 165 & & & & & & & \\
\hline 166 & & & & & & & \\
\hline 182 & 56 & 60 & 54 & 75 & 100 & 100 & 100 \\
\hline
\end{tabular}

\section{3, 5 DNT}

Ionization voltage $(\mathrm{eV})$

\begin{tabular}{|c|c|c|c|c|c|c|c|}
\hline & 75 & 50 & 30 & 20 & 18 & 16 & 14 \\
\hline 30 & 77 & 86 & 81 & 100 & 99 & 80 & 54 \\
\hline 38 & 7 & 6 & 2 & & & & \\
\hline 39 & 25 & 31 & 23 & 6 & 3 & & \\
\hline 50 & 9 & 9 & 4 & & & . & \\
\hline 51 & 13 & 16 & 12 & & & & $\therefore$ \\
\hline 52 & 10 & 13 & 13 & 4 & & & \\
\hline 53 & 7 & 10 & 11 & 10 & 7 & 3 & \\
\hline 62 & 12 & 14 & 5 & & & & \\
\hline 63 & 40 & 48 & 41 & 4 & & & \\
\hline 64 & 14 & 17 & 16 & & & & \\
\hline 65 & 6 & 7 & 8 & 6 & 4 & & \\
\hline 66 & 5 & 6 & 6 & 5. & 4 & & \\
\hline 74 & 4 & 5 & . & & & & \\
\hline 75 & 4 & 6 & 5 & & & & \\
\hline 76 & & & & & & & \\
\hline 77 & 8 & 9 & 12 & 4 & 3 & & \\
\hline 78 & 10 & 13 & 15 & 11 & 7 & 3 & \\
\hline 79 & & & & & & & \\
\hline 89 & 100 & 100 & 100 & 74 & 48 & 10 & \\
\hline 90 & 47 & 56 & 67 & 31 & 22 & 7 & \\
\hline
\end{tabular}

.

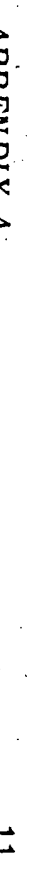


Table AII. Mass spectra of trinitrotoluene isomers at $v$ arious ionization voltages.

2, 3, 4 TNT

Ionization voltage $(\mathrm{eV})$

\begin{tabular}{llllllll} 
& 75 & 50 & 30 & 20 & 18 & 16 & 14 \\
\hline 30 & 85 & 95 & 71 & 38 & 27 & & \\
38 & & & & & & & \\
39 & 34 & 39 & 21 & 4 & 2 & & \\
46 & 16 & 16 & 11 & 8 & 4 & & \\
50 & 13 & & & & & & \\
51 & 40 & 46 & 34 & 12 & 7 & \\
52 & 15 & 16 & 14 & 7 & 3 & \\
53 & 10 & & & & 3 & \\
61 & & & & & & \\
62 & 16 & 20 & 4 & & & \\
63 & 52 & 62 & 63 & & & \\
64 & 8 & & & & & \\
65 & & & & & 3 & \\
69 & & & & & & \\
74 & $\ddots$ & & & & & \\
75 & & & & & & \\
76 & 11 & & 10 & 7 & 3 & \\
77 & 20 & 20 & 13 & 9 & 4 & \\
78 & & & & & & \\
79 & & & & & & \\
80 & & & & & & \\
86 & & & & & & \\
87 & & & & & & \\
88 & & & & & & \\
89 & 18 & 19 & 16 & 4 & &
\end{tabular}

90

91

92

93

103

104

105

106

107

116

118

119

120

$\begin{array}{rrrrrrrr}134 & 100 & 100 & 100 & 100 & 100 & 100 & 34 \\ 135 & 10 & 12 & 11 & 10 & 10 & 11 & 4\end{array}$

149

164

166

179

180

181

182

184

193

209

$\begin{array}{llllllll}210 & 48 & 57 & 51 & 50 & 51 & 77 & 77\end{array}$

$\begin{array}{llllllll}211 & 6 & 7 & 7 & 6 & 5 & 9 & 9\end{array}$

$\begin{array}{llllllll}227 & 10 & 12 & 12 & 14 & 14 & 22 & 22\end{array}$

\section{2, 3, 5 TNT}

Ionization voltage $(\mathrm{eV})$

\begin{tabular}{rrrrrrrr} 
& 75 & 50 & 30 & 20 & 18 & 16 & 14 \\
\hline 30 & 72 & 63 & 53 & 20 & 25 & 4 \\
38 & 7 & & & & & \\
39 & 27 & & 13 & 2 & & \\
46 & 7 & 6 & 5 & 2 & & \\
50 & 17 & 13 & & & & \\
51 & 48 & 37 & 32 & 7 & & \\
52 & 15 & 13 & 12 & 4 & & \\
53 & 6 & & & & & \\
61 & 6 & & & & & \\
62 & 21 & 16 & & & & \\
63 & 44 & 38 & 19 & & & \\
64 & 7 & & & & & \\
65 & 5 & & & 2 & & \\
69 & & & & & \\
74 & 6 & & & & \\
75 & 6 & 5 & & & \\
76 & 14 & 11 & 9 & 3 & \\
77 & 13 & 12 & 10 & 4 & \\
78 & 7 & 6 & 5 & 3 & \\
79 & & & & & \\
80 & & & & & \\
86 & 6 & & & & \\
87 & 8 & 5 & & & \\
88 & 5 & & & & \\
89 & 12 & 9 & 9 & 2 & \\
90 & & & & &
\end{tabular}

90

91

92

93

103

104

105

106

107

116

118

119

120

134
135

149

164

166

179

180

$\begin{array}{rrrrrrr}73 & 65 & 67 & 63 & 74 & 36 & 28 \\ 6 & 8 & 7 & 6 & 6 & 3 & \end{array}$

182

184

193

209

$\begin{array}{llllllll}210 & 100 & 100 & 100 & 100 & 100 & 100 & 100\end{array}$

$\begin{array}{llllllll}211 & 9 & 10 & 9 & 9 & 10 & 7 & 9\end{array}$

$\begin{array}{llllllll}227 & 13 & 14 & 13 & 15 & 16 & 18 & 22\end{array}$ 
Table AII (Cont'd). Mass spectra of trinitrotoluene isomers at various ionization voltages.

$$
\text { 2, 4, } 6 \text { TNT }
$$

Ionization voltage $(\mathrm{eV})$

\begin{tabular}{|c|c|c|c|c|c|c|c|}
\hline & 75 & 50 & 30 & 20 & 18 & 16 & 14 \\
\hline 30 & 41 & 65 & 45 & 36 & 39 & 17 & 15 \\
\hline 38 & 4 & 4 & & & & & \\
\hline 39 & 25 & 34 & 11 & 2 & & & \\
\hline 46 & 5 & 9 & 5 & 4 & 8 & 2 & 5 \\
\hline 50 & 12 & 17 & 6 & & & & \\
\hline 51 & 20 & 24 & 12 & 2 & & & \\
\hline 52 & 5 & 7 & 4 & 2 & & & \\
\hline 53 & 4 & 5 & 4 & 2 & & & \\
\hline 61 & 6 & 5 & & 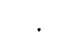 & & & \\
\hline 62 & 21 & 33 & 7 & & & & \\
\hline 63 & 38 & 61 & 24 & 2 & & & \\
\hline 64 & 8 & 12 & 7 & 4 & & & \\
\hline 65 & 8 & 10 & 7 & 6 & 7 & 3 & 4 \\
\hline 69 & 6 & 7 & 5 & 6 & & & \\
\hline 74 & 11 & 12 & 3 & & & & \\
\hline 75 & 9 & 14 & 6 & & & $\vdots$ & \\
\hline 76 & 20 & 28 & 18 & 9 & & & \\
\hline 77 & 11 & 16 & 10 & 8 & & & \\
\hline 78 & 6 & 6 & 5 & 5 & 7 & 4 & \\
\hline 79 & & & & & & & \\
\hline 80 & & & & & & & \\
\hline 86 & 7 & 7 & & & & & \\
\hline 87 & 9 & 12 & & & & & \\
\hline 88 & 10 . & 15 & 8 & & & & \\
\hline 89 & 48 & 67 & 43 & 6 & & & \\
\hline 90 & 6 & 10 & 7 & & & & \\
\hline 91 & & & & & & & \\
\hline 92 & 6 & 5 & 4 & & & & \\
\hline 93 & & & & & & & \\
\hline 103 & 4 & 4 & 3 & & & & \\
\hline 104 & 4 & 7. & 5 & & & & \\
\hline 105 & 6 & 7 & 6 & 6 & 7 & 3 & \\
\hline 106 & 5 & 6 & 5 & 4 & & & \\
\hline 107 & & & & & & & \\
\hline 116 & 3 & & & & & & \\
\hline 118 & & $\therefore$ & & & & & \\
\hline 119 & & & & & & & \\
\hline 120 & 4 & 6 & 4 & & & & \\
\hline 134 & 16 & 22 & 16 & 12 & 10 & 6 & \\
\hline 135 & 4 & & 3 & & & & \\
\hline 149 & 12 & 16 & 12 & 14 & 14 & 16 & 16 \\
\hline 164 & 6 & 7 & 7 & 8 & 13 & 3 & \\
\hline 166 & 4 & 6 & 5 & 3 & & & \\
\hline 179 & 8 & 11 & 9 & 12 & 15 & 8 & 11 \\
\hline 180 & 15 & 17 & 14 & 15 & 15 & 7 & 6 \\
\hline 181 & & & & & & & \\
\hline 182 & & & & & & & \\
\hline 184 & & & & & & & \\
\hline 193 & 13 & 18 & 13 & 14 & 19 & 2 & \\
\hline 209 & 5 & 6 & 5 & 8 & 9 & 7 & 13 \\
\hline 210 & 100 & 100 & 100 & 100 & 100 & 100 & 100 \\
\hline 211 & 10 & 12 & 9 & 11 & 11 & 12 & 11 \\
\hline 227 & 3 & 4 & 3 & 4 & 4 & 4 & 3 \\
\hline
\end{tabular}


Table AII (Cont'd). Mass spectra of trinitrotoluene isomers at various ionization voltages.

Table AII (Cont'd). Mass spectra of trinitrotoluene isomers at various ionition
$2,3,5$ TNT

\begin{tabular}{|c|c|c|c|c|c|c|c|c|c|c|c|c|c|c|c|c|}
\hline & 75 & 50 & 30 & 20 & 18 & 16 & 14 & & & 75 & 50 & 30 & 20 & 18 & 16 & 14 \\
\hline 30 & 85 & 96 & 83 & 47 & 34 & 20 & 14 & & 30 & 88 & 73 & 70 & 87 & 79 & 52 & 38 \\
\hline 38 & 15 & & & & & & & & 38 & & & & & & & \\
\hline 39 & 47 & 41 & 21 & & & & & & 39 & 24 & 19 & 11 & & & & \\
\hline 46 & 8 & & & & & & & & 46 & 5 & 5 & & & & & \\
\hline 50 & 26 & 23 & 9 & & & & & & 50 & 16 & 10 & 4 & & & & \\
\hline 51 & 71 & 61 & 46 & & & & & & 51 & 38 & 30 & 24 & 6 & & & \\
\hline 52 & 16 & 14 & 11 & & & & & & 52 & 14 & 13 & 11 & 7 & & & \\
\hline 53 & 12 & 9 & 8 & & & & & & 53 & 8 & 6 & 7 & & & & \\
\hline 61 & 10 & & & & & & & . & 61 & & & & & & & \\
\hline 62 & 35 & 20 & 8 & & & & $=$ & & 62 & 17 & 13 & 5 & & & & \\
\hline 63 & 78 & 61 & 28 & & & & & & 63 & 33 & 29 & 16 & & & & \\
\hline 64 & 18 & 13 & 14 & & & & & & 64 & 6 & 5 & 5 & & & & \\
\hline 65 & 9 & 8 & 7 & & & & & & 65 & 6 & 6 & 4 & 4 & & & \\
\hline 69 & & & & & & & & & 69 & & & & & & & \\
\hline 74 & 11 & 11 & & & & & & & 74 & & & & & & & \\
\hline 75 & 19 & 10 & 5 & & & & & & 75 & 5 & & & 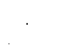 & & & \\
\hline 76 & 28 & 17 & 14 & & & & & & 76 & 14 & 15 & 13 & 5 & & & \\
\hline 77 & 23 & 17 & 15 & 3 & & & & & 77 & 10 & 9 & 8 & 4 & & & \\
\hline 78 & 15 & 10 & 10 & 3 & & & & & 78 & 5 & 8 & 8 & 6 & & & \\
\hline 79 & 6 & & 5 & & $:$ & & & & 79 & & & & & & & \\
\hline 80 & 12 & 7 & 8 & & & & & & 80 & & & & & & & \\
\hline 86 & 9 & & & & & & & & 83 & 5 & & & & & & \\
\hline 87 & 15 & 8 & & & & & & & 87 & 7 & & & & & & \\
\hline 88 & 5 & & & & & & & & 88 & & & & & & & \\
\hline 89 & 15 & 12 & 10 & & & & & & 89 & & & & & & & \\
\hline 90. & 17 & 9 & 9 & & & . & & & 90 & & & & & & & \\
\hline 91 & 6 & & & & & 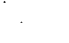 & & & 91 & & & & & & & \\
\hline 92 & 7 & & 4 & & & & & & 92 & & & & & & & \\
\hline 93 & 9 & 6 & 5 & & & ' & & & 93 & & & & & & & \\
\hline 103 & & & & & & & & & 103 & & & & & & & \\
\hline 104 & 9 & 6 & 6 & & . & & & & 104 & & . & & & & & \\
\hline 105 & 15 & 11 & 11 & 11 & 12 & 6 & 6 & & 105 & & & & & & & \\
\hline 106 & 13 & 8 & 49 & 7 & & & & & 106 & & & & & & & \\
\hline 107 & 9 & 4 & 5 & & & & & & 107 & & & & & & & \\
\hline 116 & & & & & & & & & 116 & & & & & & & \\
\hline 118 & 6 & 4 & & & & & & & 118 & 13 & 11 & 14 & 12 & 7 & 14 & \\
\hline 119 & 5 & & & & & & & & 119 & & & & & & . & \\
\hline 120 & 6 & & & & & & & & 120 & & & & & & & \\
\hline 134 & 44 & 31 & 32 & 29 & 18 & 11 & 8 & & 134 & & & & & & & \\
\hline 135 & 6 & & 4 & & & & & & 135 & & & & & & & \\
\hline 149 & 15 & 10 & 10 & 11 & 9 & 9 & 12 & & 149 & & & & & & & . \\
\hline 164 & & & & & & & & & 164 & & & & & & & \\
\hline 166 & & & & & & & & & 166 & & & & & & & \\
\hline 179 & & & & & & & & & 179 & & & & & & & \\
\hline 180 & 32 & 28 & 30 & 26 & 25 & 21 & 22 & & 180 & & & & & & & \\
\hline 181 & & & & & & & & & 181 & & & & & & & \\
\hline 182 & 4 & & & & & & & 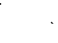 & 182 & & & & & & & \\
\hline 184 & & & & & & & & & 184 & 13 & 11 & 14 & 12 & 7 & 14 & \\
\hline 193 & 6 & & & & & & & & 193 & & & & & & & \\
\hline 209 & & & & & & & $\therefore$ & & 209 & & & & & & & \\
\hline 210 & 100 & 100 & 100 & 100 & 100 & 100 & 100 & & 210 & 100 & 100 & 100 & 100 & 100 & 100 & 100 \\
\hline 211 & 14 & 10 & 9 & 10 & 9 & 8 & 12 & & 211 & 11 & 11 & 12 & 12 & 9 & 12 & 40 \\
\hline 227 & 14 & 8 & 8 & 8 & 8 & 8 & 13 & & 227 & 20 & 22 & 27 & 30 & 28 & 27 & 49 \\
\hline
\end{tabular}


Table AIIl. Mass spectra of trinitrotoluene based explosives.

Sample designations correspond to labels on samples by Mr. M. Kemp, USA MERDC. Ionization volt age $=75 \mathrm{eV}$.

\begin{tabular}{|c|c|c|c|}
\hline \multirow[b]{2}{*}{$m / e$} & \multicolumn{3}{|c|}{ TNT Sample } \\
\hline & DCT 1 & $D C T 2$ & DCT 3 \\
\hline 30 & 50 & 48 & 59 \\
\hline 38 & 5 & 5 & 4 \\
\hline 39 & 27 & 27 & 28 \\
\hline 46 & 6 & 6 & 6 \\
\hline 50 & 14 & 15 & 16 \\
\hline 51 & 18 & 19 & 21 \\
\hline 52 & 6 & 6 & 7 \\
\hline 53 & 4 & 4 & 5 \\
\hline 61 & 5 & 6 & 6 \\
\hline 62 & 24 & 27 & 28 \\
\hline 63 & 44 & 48 & 62 \\
\hline 64 & 8 & 9 & 8 \\
\hline 65 & 7 & 8 & 8 \\
\hline 69 & 6 & 6 & \\
\hline 74 & 9 & 11 & 12 \\
\hline 75 & 10 & 13 & 15 \\
\hline 76 & 22 & 22 & 15 \\
\hline 77 & 11 & 6 & 11 \\
\hline 78 & 5 & 7 & 14 \\
\hline \multicolumn{4}{|l|}{79} \\
\hline \multicolumn{4}{|l|}{80} \\
\hline 86 & 7 & 7 & 10 \\
\hline 87 & 9 & 11 & 8 \\
\hline 88 & 11 & 14 & 9 \\
\hline 89 & 52 & 57 & 52 \\
\hline 90 & 8 & 9 & 8 \\
\hline \multicolumn{4}{|l|}{91} \\
\hline \multicolumn{4}{|l|}{92} \\
\hline \multicolumn{4}{|l|}{93} \\
\hline 103 & 3 & 5 & 6 \\
\hline 104 & 4 & 6 & 6 \\
\hline 105 & 6 & 6 & 7 \\
\hline 106 & 4 & 5 & 5 \\
\hline \multicolumn{4}{|l|}{107} \\
\hline \multicolumn{4}{|l|}{116} \\
\hline \multicolumn{4}{|l|}{118} \\
\hline \multicolumn{4}{|l|}{119} \\
\hline 120 & 5 & 5 & 6 \\
\hline 134 & 14 & 16 & 20 \\
\hline \multicolumn{4}{|l|}{135} \\
\hline 149 & 9 & 10 & 16 \\
\hline 164 & 5 & 6 & 9 \\
\hline 166 & 4 & 4 & 6 \\
\hline 179 & & & 9 \\
\hline 180 & 13 & 14 & 19 \\
\hline \multicolumn{4}{|l|}{181} \\
\hline \multirow{2}{*}{\multicolumn{4}{|c|}{$\begin{array}{l}182 \\
184\end{array}$}} \\
\hline 184 & & & \\
\hline 193 & 11 & 12 & 15 \\
\hline \multicolumn{4}{|l|}{209} \\
\hline 210 & 100 & 100 & 100 \\
\hline 211 & 10 & 10 & 13 \\
\hline 227 & $<1$ & $<1$ & 3 \\
\hline
\end{tabular}


DOCUMENT CONTROL DATA - R \& D

securty clascitication of tille, budy of abstract and indexing annotation must be entered when the uverall repoll is clasollled; QRICINATIUG ACTIVIT (Comorate author)

U.S. Army Cold Regions Research

and Engineering Laboratory

Hanover, New Hampshire 03755

- RE CAT TI:LE

COMPOSITION AND MASS SPECTRA OF IMPURITIES IN MILITARY GRADE TNT VAPOR

4 DESCRIPTIVE NOTES (TYPo of roporl and inclusive dates)

s AUTHOR(S) (First namo, middle initlal, last namo)

R.P. Murrmann, T.F. Jenkins, and D.C. Leggett

\begin{tabular}{|c|c|}
\hline $\begin{array}{l}\text { Q. REPORTDATE } \\
\text { May } 1971 \\
\end{array}$ & \begin{tabular}{|c|c|} 
7a. TOTAL NO. OF PAGES & 7b. NO. OF REFS \\
14 & 18 \\
\end{tabular} \\
\hline BA. CONTRACT OR GRANT NO. & DQ. ORIGINATOR'S REPORT NUMBEERIS) \\
\hline b. PROJECTNO. 1J $662708 \mathrm{~A} 462$ & Special Report 158 \\
\hline & 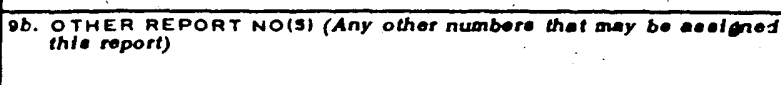 \\
\hline
\end{tabular}

10. DISTRIBUTION STATEMENT

Approved for public release; distribution unlimited.

11. SUPPLEMENTARY NOTES

12. SPONSORING MILITARY ACTIVITY

U.S. Army Mobility Equipment Research and Development Center

13. ABSTRACT

Characterization of the vapor from explosives is required for development of mine and explosives detection systems based upon trace gas analysis. This study was undertaken to evaluate the suitability of gas chromatographic electron capture techniques for investigating the composition of military grade TNT vapor, and to determine the mass spectra of the components in the vapor phase. Using a gas chromatographic method, the DNT and TNT isomeric impurities in vapor in equilibrium with typical military grade TNT were established: The 2, 4 DNT content of the vapor was almost as high as that of 2, 4, 6 TNT, the major component of the solid TNT. Mass spectra of all possible DNT and TNT isomers with the exception of 3, 4, 5 TNT were obtained as a function of ionization voltage. Mass spectra were also taken of several military grade TNT samples. Mass peaks common to both 2,4 DNT and $2,4,6$ TNT at m/e $=63$ and 89 may be diagnostic for TNT using fragment ion type detection systems in that these peaks are not found in the mass spectra of compounds present in the atmosphere.

14. KEY WORDS

Explosives detection

Mass spectra

Dinitrotoluene.

Mine detection
Trace gas

Trinitrotoluene 